\title{
Spatiotemporal dynamics of snow erosion, deposition and horizontal mass flux
}

\author{
PHILIP CRIVELLI, ${ }^{1 *}$ ENRICO PATERNA, $^{1}$ MICHAEL LEHNING ${ }^{1,2}$ \\ ${ }^{1}$ WSL-Institute for Snow and Avalanche Research SLF Flüelastrasse 11, CH-7260 Davos Dorf, Switzerland \\ ${ }^{2}$ CRYOS, School of Architecture, Civil and Environmental Engineering Ecole Polytechnique Federal de Lausanne, \\ CH-1015 Lausanne, Switzerland \\ Correspondence: Philip Crivelli <philip.crivelli@slf.ch>
}

\begin{abstract}
The quantification of snow transport, both in wind tunnels and the field, apply particle counting methods limited to punctual sampling of relatively small volumes. Particle counting can only capture horizontal mass fluxes, failing to measure snow erosion or deposition. Herein, we present a novel low-cost sensor tool, based on a Microsoft Kinect, adapted to capture snow surface changes during snow drifting at unprecedented spatial and temporal resolutions. In the wind tunnel setting of these experiments we observe a balance between erosion and deposition at low wind speeds, while erosion is dominant at higher wind speeds. Significant differences in power spectral densities of surface mass flux and horizontal particle mass flux are observed. We show that for the saltationlength-scale parameter $\lambda=1$, the integrated particle flux can be used to estimate the total surface mass flux in the wind tunnel. This provides an important basis to interpret mass flux measurements in the field.
\end{abstract}

KEYWORDS: mass-balance reconstruction, snow/ice surface processes, wind-blown snow

\section{INTRODUCTION}

Wind is the principal erosion mechanism of granular surfaces such as sand or snow, known as aeolian transport. Kok and others (2012) provide an overview of the three modes of aeolian transport, creep, saltation and suspension. Creep describes the rolling and sliding of large particles along a surface, without becoming fully airborne (Bagnold, 1937). Saltation describes the movement of particles along ballistic trajectories following entrainment by the fluid drag or ejection by impacting particles (Bagnold, 1941); and are often referred to as drifting particles. Suspension describes the process of particles that follow the turbulent motion of eddies and may remain airborne for a long period of time. Suspension is often characterized by the time that the particles are in the air and by the diameter of the particles, which is generally very small (Gillette and Walker, 1977; Zender and others, 2003; Miller and others, 2006). Aeolian transport is initiated when the winds shear force acting on the bed exceeds a particle entrainment threshold. The threshold between each transport mode is different and largely influenced by the size of the particles, their material properties (cohesion between particles (Schmidt, 1982) and particle geometry or surface structures (Doorschot and others, 2004; Clifton and others, 2006; Filhol and Sturm, 2015)). Aeolian transport induces an evolution of the snow surface morphology. Particles are entrained and transported along the surface. Interactions of particles with other particles alter the surface morphology generating structures such as ripples, sastrugi, dunes or cornices. Given that both sand and snow exhibit similar aeolian surface structures, many studies have focussed on the behaviour of drifting sand particles. However, snow exhibits a number of differences to sand that render it unsatisfactory to use as an analogue for snow studies.

* Present address: WSL-Institute for Snow and Avalanche Research SLF Flüelastrasse 11CH-7260 Davos DorfSwitzerland.
Models of drifting sand and snow often assume a steady flux in equilibrium with a certain (mean) wind speed (Bagnold, 1941; Kawamura, 1951; Owen, 1964; Dong and others, 2003). However, recent studies (Groot Zwaaftink and others, 2013; Walter and others, 2014) show that this equilibrium is an approximation, particularly for snow. It is shown that snow flux rates are highly unsteady and not coupled to constant wind speeds but rather to wind fluctuations (Paterna and others, 2016). Many of the differences observed in mass flux between sand and snow can be attributed to the differences in material properties. For example, Schmidt (1980) shows that cohesion forces between snow particles are much larger than gravitational forces, which can explain many of the differences observed in the saltation behaviour between snow and sand.

A large number of studies looked at the numbers of particles drifting in the saltation layer, either in field experiments in alpine regions (Schmidt and others, 1984; Meister, 1987; Gordon and Taylor, 2009; Gordon and others, 2009; Naaim-Bouvet and others, 2010, 2011) or in polar regions (Nishimura and Nemoto, 2005). Many experiments were performed in cold wind tunnels (Nishimura and others, 1998; Clifton and others, 2006) or used a modelling approach. The majority of these studies focussed on the transport of snow in the saltation layer using snow particle counters therefore neglecting the contribution of creep and suspension modes. Studies observing the evolution of snow surface morphology were performed using terrestrial laser scanner (Trujillo and others, 2007, 2016; Grünewald and others, 2010) or by modelling the saltation and surface erosion (Meister, 1988; Pomeroy, 1991; Michaux and others, 2002; Doorschot and others, 2004; Vionnet and others, 2013; Comola and Lehning, 2017). In studies using terrestrial laser scans or aerial images, the temporal resolution is coarse, limited to multiple hours or days (before and after a storm or snow fall event). Herein, we discuss 
the dynamics of snow drifting through surface erosion and deposition captured at high temporal resolutions in a cold wind tunnel. In particular, we provide insights into the relationship between eroded snow surface volume and the number of particles in saltation mode recorded with a Snow Particle Counter (SPC). Furthermore, we examine how temporal scales of surface erosion influence the mass flux maxima and draw conclusions on the spatiotemporal dynamics of the erosion process. The first section introduces the experimental setup, in particular, the novel Kinect sensor developed as a low cost device to scan the snow surface during the experiments. The following section examines the results of this new approach with respect to the dynamics and quantity of the mass flux due to snow surface erosion. We discuss the total set-averaged mass-flux, based on the difference between surface height measurements captured before and after experimental wind tunnel runs, representing the net eroded/deposited snow during experimentation. We then provide observations of the correlation between the integrated particle and surface mass fluxes. This is performed with respect to size if the observed surface area (support area) as well as the saltation length scale used for the formulation of the saltation profile. Finally, we focus on the spectral mass flux distribution with respect to the differences between particle and surface mass flux. Based on these results we discuss the dynamics of surface erosion and how it affects the particle mass flux in the saltation layer.

\section{METHODS AND INSTRUMENTATION}

The experiments were conducted in a cold wind tunnel located at $1670 \mathrm{~m}$ a.s.I in the Flüela valley near the Snow and Avalanche Research Centre (SLF) in Davos, Switzerland. The tunnel has a $6 \mathrm{~m}$ long fetch roughness consisting of a row of spires and roughness elements. Following this, an $8 \mathrm{~m}$ long snow cover section completes the tunnel with the measurement instrumentation at the end. The tunnel inlet is composed of a honeycomb grid followed by a 4:1 contraction. The wind tunnel is operated through suction which draws air through the inlet. The snow used during experimentation was natural snow collected in metal trays outside the wind tunnel building. The tunnel was first introduced by Clifton and others (2006). An experiment required a between $0.07 \mathrm{~m}$ and $0.15 \mathrm{~m}$ of fresh snow (Fig. 1).

A propeller-type anemometer with an integrated thermometer (MiniAir 20, Schildknecht AG, Switzerland) was used to record the free-stream velocity $\left(U_{\text {free }}\right)$, the temperature and the relative humidity $(\mathrm{RH})$ in the wind tunnel. Particles in the saltation layer were recorded using the SPC sensor (SPC - S7, Niigata Denki Co.) as first introduced by Nishimura and others (1998) and Sugiura and others (1998). This method of counting snow particles is based on the voltage change induced as snow particles pass the SPC's photodiode. Based on the amplitude of the voltage signal, a classification of the particle's diameter into 32 size classes between 0.04 and $0.5 \mathrm{~mm}$ is possible. The distance between the SPC and the snow surface could be accurately positioned with a traverse stage, which ensured the SPC measurements were taken at a constant $20 \mathrm{~mm}$ from the snow surface for each experiment. A drawback of this setup is that particles at the onset of saltation travelling below the height of $20 \mathrm{~mm}$ could not be detected. During a number of experiments, saltation below $20 \mathrm{~mm}$ was observed to influence snow surface change. Surface erosion (including creep) already starts at low wind speeds close to the threshold wind speed at which the SPC measurements at $20 \mathrm{~mm}$ do not record sufficient particles for reliable flux estimates. Addressing this limitation, we applied Microsoft's 'Kinect for Windows'-device to capture snow surface changes during the experiment. The Kinect was first introduced in 2010 as a low-cost motion sensing input device for a video game console. It consists of an infra red (IR) emitter and sensor, a colour camera, a microphone array and a tilt motor. The sensor module was mounted on the wind tunnel roof using scaffolding. The principal sensor applied in this study was the IR emitter/sensor pair, which captured three-dimensional depth images of the snow surface. Besides the hardware, Microsoft also released a software platform to develop customized software for the Kinect devices. Kinect devices are widely used in other fields such as machine learning (Yavsan and Ucar, 2016) and medical studies (Prochazka and others, 2016). Mankoff and Russo (2012) discussed possible applications of the Kinect sensor in Earth sciences. Nicholson and others (2016) demonstrate the application of a Kinect device to measure glacial penitentes. One advantage that the Kinect sensor has over traditional photogrammetric setups is that it comes precalibrated and does not require reference points (see subsection Kinect mass flux computation).

\subsection{Experiments}

All experiments presented in this study applied stepped increases of wind speed. Wind speeds started below the threshold for snow particle entrainment and were increased to reach values that induced strong erosion. Between the beginning of January 2016 and March 2016, we performed experiments on 7 separate days. A total number of 115 wind speed steps were recorded. Each step in wind speed lasted $\sim 60 \mathrm{~s}$. The snow density was recorded before experimentation on each test day, and was later used in the surface mass flux calculations.

The Kinect device roof mounting in the wind tunnel oriented the sensors perpendicular to the snow surface. Depth and colour images were recorded using software based on the Kinect Stream Saver application by Dolatabadi and others (2014). The software permitted depth and colour image capture at $30 \mathrm{~Hz}$ with a resolution of $640 \times 640$ pixels. The Kinects field of view (FOV) partly overlapped with the SPC; the pixels containing this overlap were ignored in the analysis. Before recording of each wind step, the height of the SPC was adjusted to $20 \mathrm{~mm}$ above the snow surface. This was necessary for each wind step change due to the snow surface erosion incurred during the previous wind step. The threshold freestream velocity $U_{\text {free,t }}$ was chosen to be the wind speed at which the SPC was able to detect the first few particles. This point might seem to be a little vague, but it allowed separation between artefacts from the mounting of the snow trays in the wind tunnel and the actual wind-induced erosion.

\subsubsection{Kinect mass flux computation}

The distance between sensor and snow was below $1 \mathrm{~m}$, which allowed for a $0.90 \times 0.68 \mathrm{~m}$ sensor footprint that could be evaluated. In the post-processing phase this area was reduced in order to avoid pixel overlap with the area 


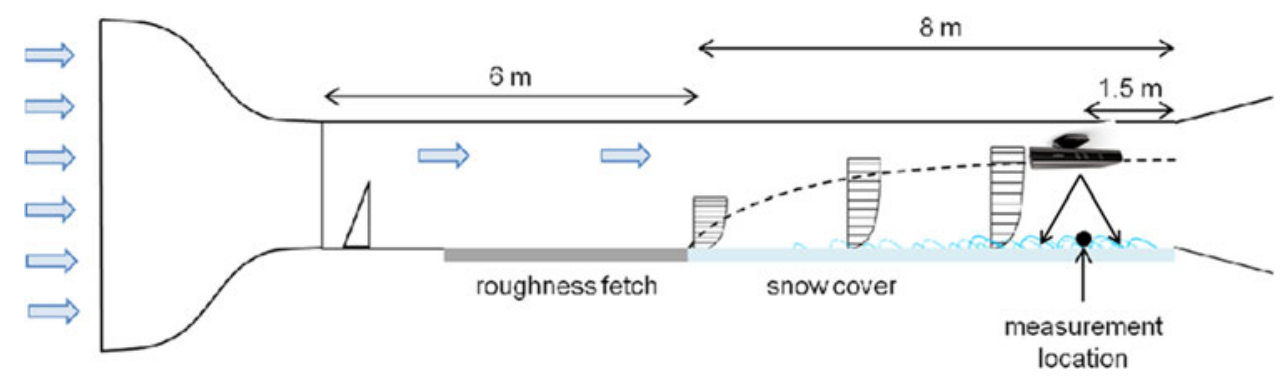

Fig. 1. Schematic overview of the wind tunnel, including the location of the Kinect device. The Kinect was attached to the wind tunnel ceiling to capture the snow surface change beneath it.

of the SPC. At this range, the Kinect depth sensor precision is $1 \mathrm{~mm}$. The distance between sensor and target determines the resolution in the horizontal field of view (FOV) because the sensor has a set number of pixels. For the experimental setup this gave an average pixel area of $\sim 0.3 \mathrm{~mm}^{2}$. Studies looking at the accuracy of the depth sensor (Essmaeel and others, 2014) mention the requirement for data filtering to avoid signal noise. Essmaeel and others (2012) describe a temporal de-noising filter that addresses this issue. In the present application, the filtering was not required in realtime, it was sufficient to apply it in a post-processing phase. Application of temporal de-noising did not improve data quality in comparison with common moving average filters. Given the Kinects' noisy signal, the time series depth data re-sampled for each pixel from $30 \mathrm{~Hz}$ to $1 \mathrm{~Hz}$ applying a Savitzky-Golay moving average filter from MATLAB's sgolayfilt function. In addition to the temporal moving average filter, we added a spatial 2-D adaptive noise removal filter (MATLAB's wiener2 function). The wiener2 function was applied to reduce the characteristic Kinect IR noise. After smoothing the time series depth data, they were differentiated to compute the change of the snow surface. This was achieved by calculating the time-derivative for the depth of each pixel, and was applied to the entire event time series. The Kinect device is able to calculate a 3-D coordinate for each pixel using the skeletal stream framework provided in its stream saver software. Within this study, this would have resulted in vast amount of data. Therefore, the postprocessing applied a trigonometric approach to calculate the $x$ and $y$ coordinates of each pixel, which was achieved with the following formula:

$$
\begin{gathered}
\left.x_{i, j}=2 \tan \left(\beta \cdot\left(j-h / 2+X_{o}\right) \cdot z_{i, j}\right)\right), \\
\left.y_{i, j}=-2 \tan \left(\alpha \cdot\left(i-w / 2+Y_{o}\right) \cdot z_{i, j}\right)\right)
\end{gathered}
$$

where $\beta$ is the angle of the depth sensors FOV along the $x$ direction, and $\alpha$ the angle along $y$-direction. The calculated angles $\alpha$ and $\beta$ were validated against the skeletal stream data. $X_{O}$ and $Y_{O}$ represent the offset to the centreline of the FOV in the respective direction. $h$ gives the total number of pixels in the $x$-direction, and $w$ the total number in $y$ direction. The symbol $i$ represents the $i$-th pixel in $x$-direction, $j$ represents the $j$-th pixel in $y$-direction. In order to estimate the quality and precision of the Kinect device, we first conducted a calibration study. The geometrical calibration setup is shown in Figure 2. Firstly, the fresh snow surface was scanned with the Kinect. Following this, three uniform $40 \mathrm{~mm} \times 40 \mathrm{~mm} \times 80 \mathrm{~mm}$ wooden elements were carefully pressed into snow surface creating depressions in the surface, which were then scanned. The snow height difference between each scan provided the calibration required, whereby it was possible to demonstrate that the device measures the correct dimensions of the snow surface and impressions left by the wooden elements. From the calibration tests, we estimated the absolute measurement accuracy of snow depth to be $1 \mathrm{~mm}$. However, by performing the previously described post processing, the uncertainty between consecutive measurements is lower (since the $1 \mathrm{~mm}$ precision is averaged to values below $1 \mathrm{~mm}$ ), as is described by Essmaeel and others (2012).

The change of volume at each pixel $d V_{i, j}$ was calculated based on the average pixel $A_{i, j}$ area and the change in depth $d z_{i, j}$

$$
d V_{i, j}=A_{i, j} \cdot d z_{i, j}
$$

The change of mass per unit area and time for each pixel (mass flux $q_{i, j}$ ) is then calculated as the volume changes multiplied by the snow density $\rho_{\text {snow }}$ and the time between the time steps as the inverse sampling frequency $f_{\mathrm{s}}$ and the total measurement area $A$

$$
q_{i, j}=\frac{\rho_{\text {snow }}}{A} \cdot f_{s} d V_{i, j}
$$

The sum of the mass flux over all pixels divided by the total number of pixels per frame $N$ gives the total surface mass flux $q_{\mathrm{s}}$.

$$
q_{\mathrm{S}}(t)=\frac{1}{N} \sum_{i, j} q_{i, j}
$$

Integration of the mass flux and mass flux time series by the total run time gives the total time-averaged mass flux $Q_{s}$.

$$
Q_{\mathrm{S}}=\int_{t_{0}}^{t_{\mathrm{end}}} q_{\mathrm{S}}(t) \mathrm{d} t
$$

In addition to the mass fluxes, we calculated the surface height difference between the first and last frame recorded in a set, which gives the total surface volume change. If the total surface volume change is multiplied by the density of the snow and normalized by the total runtime of the set and surface area, the total set-averaged mass flux $Q_{\mathrm{SB}}$ can be obtained. This gives a measure of the total set-averaged mass flux balance. The main difference between the calculations of the time-averaged surface mass flux is the sampling time. In order to observe the influence of the size of the support area, we introduced a reduction factor (RF) with 

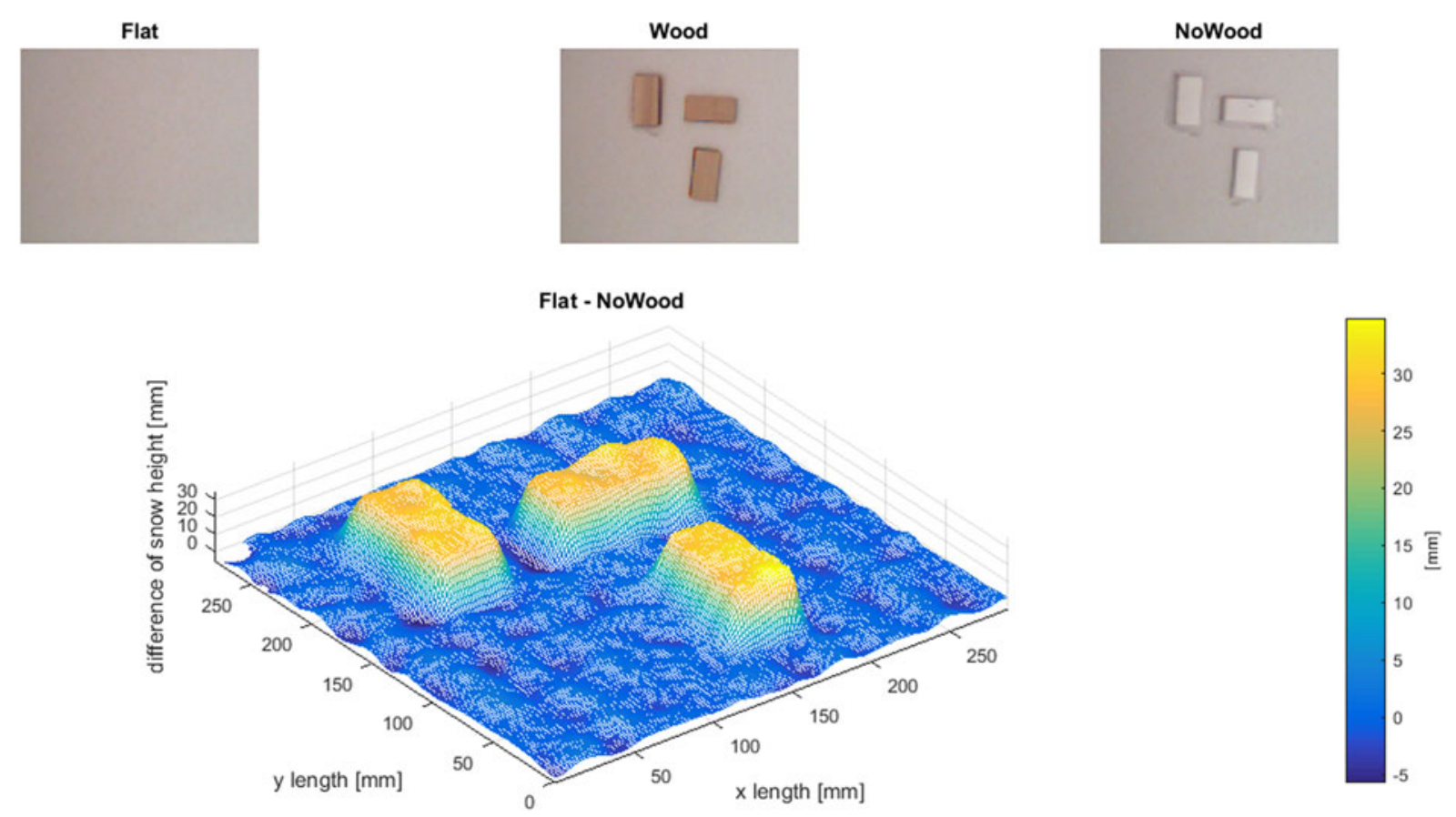

Fig. 2. Kinect calibration setup. Kinect colour view to the snow with and without wooden elements (upper row). Change of surface height between original snow surface and the snow surface with the impressions of the wooden elements.

the values 1, 2, 4, 8 and 16. The RF acted as the approximate partition of the initial surface area (i.e. $R F=1$, no reduction, $R F=2$, half of a side length and so on). For more details on the $R F$ factor, please refer to the Appendix.

\section{SPC mass flux computation}

While the Kinect's depth sensor is able to measure the mass flux based on the change of the snow cover (net vertical flux), the SPC measures the saltation mass flux (horizontal flux) on a small volume in the saltation layer above the snow cover. Following Kawamura (1948, 1951); Dong and Qian (2007) who express the mass flux profile as an exponential decay; we applied

$$
q_{\mathrm{P}}(z)=q_{0} \cdot \mathrm{e}^{-b \cdot\left(z-h_{0}\right)},
$$

where $q_{0}$ is the average SPC mass flux of the time series at the
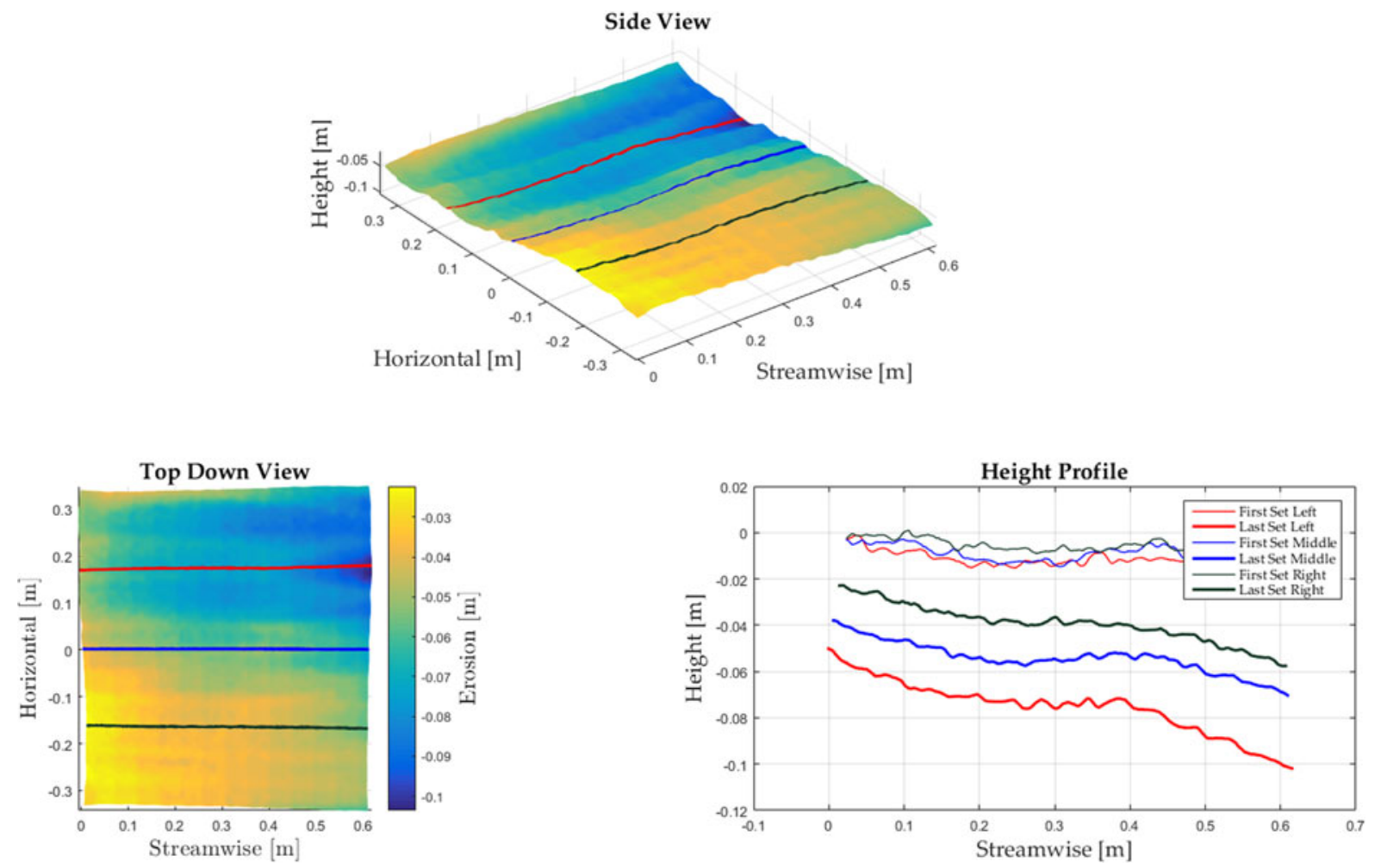

Fig. 3. Kinect erosion depth in side view (top), in plan-view (left) and the profiles from before and after a test (right). 
moment of measurement and $h_{0}$ is the height of the SPC measurement above the snow surface. Literature presenting the exponential decay function, for example Rasmussen (1985); Nalpanis and others (1993); Dong and Qian (2007), indicate large variability for the parameter $b$. The parameter $b$, applied herein, corresponds to the inverse of what is referred to as the saltation system length scale $L=u_{*}^{2} /(\lambda g)$ (Guala and others, 2008). $u_{*}$ is the friction velocity, $\lambda$ is a constant defining $L$ and $g$ represents the gravitational constant. The value of $\lambda$ varies in the literature. For calculations presented herein, we applied $b$ based on values by Clifton and others (2006) and Guala and others (2008) from experiments performed in the same wind tunnel $(L=0.022)$. In addition, we performed a sensitivity analysis for values of $\lambda$ between 0.18 and 1.17 (see appendix, and Table 5) to investigate how $\lambda$ alters the relation between surface and particle mass flux. As described by Guala and others (2008), a small $\lambda$ extends the height of the saltation layer, where a $\lambda$ that approaches unity confines the saltation layer close to the surface. The estimation of $u_{*}$ was achieved according to Gromke and others (2011) following the law-of-the-wall, using the averaged free stream wind velocity.

The vertical expansion of the saltation layer was assumed to have a maximal height of $z_{\mathrm{SL}}=0.12 \mathrm{~m}$, and corresponded to an estimation based on visual inspections during the experiments. Since previous experiments in the same wind tunnel (Gromke and others, 2014) reported an exponential decay of the particle number with height, the chosen number seemed reasonable. The mass flux recorded by the SPC is integrated over the total height from $z=0$ to $z=z_{\mathrm{SL}}$.

Assuming a linear increase of erosion along the streamwise direction, the divergence of the vertically integrated mass flux profile $Q_{\mathrm{P}}$ was calculated. Assuming a linear increase in erosion, the divergence was calculated according to the division of the integrated mass flux by the erosion footprint length $L_{P}$.

$$
Q_{\mathrm{P}}=\frac{\int_{0}^{z_{\mathrm{SL}}} q_{\mathrm{P}} d z}{L_{\mathrm{P}}}
$$

The footprint was estimated as the length before the particle counter at which the snow surface was eroded. In the case of the wind tunnel, where the saltation system develops after a rather short fetch length from zero, the first few metres of the snow surface appeared unchanged after each experiment; independent of snow properties. The calculation of footprint length $L_{P}$ is illustrated in Figure 4. The footprint length corresponds to the length, in which the snow surface is eroded assuming a linear increase of surface erosion with the fetch length. The calculated length $L_{P}$ was in good agreement with the approximate length obtained through visual inspection.

\section{RESULTS AND DISCUSSION}

The experimental conditions during this study are summarized in Table 1. Figure 5 displays a representative example of results during a test day that illustrates the dynamics of the surface erosion. Table 2 presents the mean free stream velocity and the net surface mass flux for the two sets in the example. The particle size distribution recorded with the SPC (not shown) for the two sets were very similar. We observed a reduction in the average particle diameter on the individual test days. One process leading to this

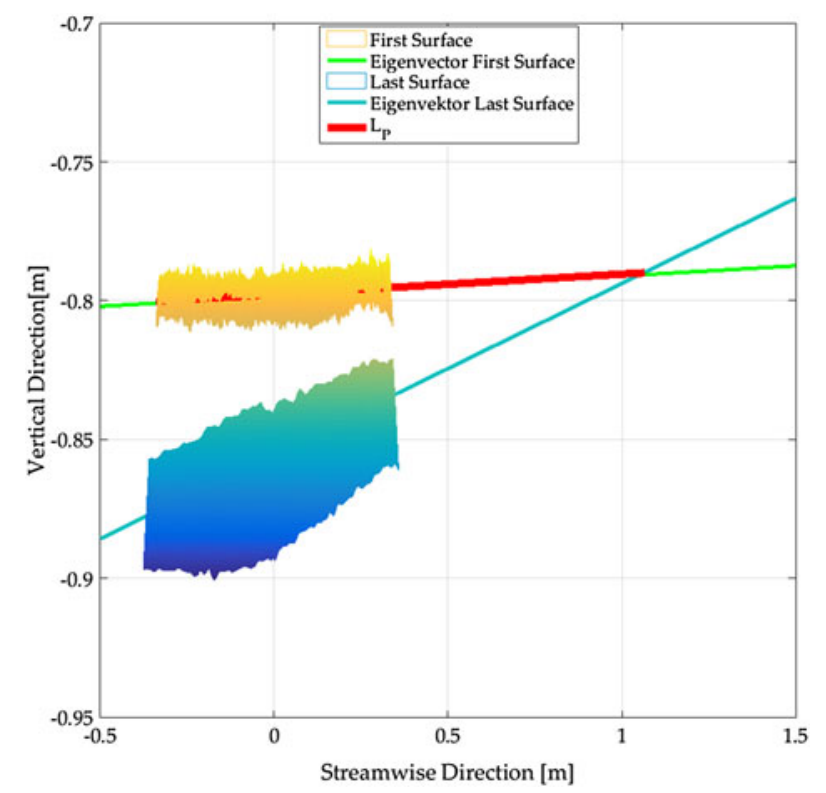

Fig. 4. Procedure to calculate the saltation footprint length based on the values from Test Day 3. By means of the principal component analysis (PCA) the orthogonal eigenvalues for the snow surface before the experiment (First Surface) and the surface at the end of the experiment (Last Surface) were calculated. Using the two orthogonal, streamwise eigenvectors as well as the difference in height between the untouched surface before and after the end of the experiment, a point of intersection between the two orthogonal vectors could be calculated. The length $L_{P}$ was then given by the distance between the SPC and the point of intersection.

Table 1. Experiments in the winter season 2016

\begin{tabular}{lcccccc}
\hline Test day & Date & $U_{\text {free, }}\left[\frac{\mathrm{m}}{\mathrm{s}}\right]$ & $\rho\left[\frac{\mathrm{kg}}{\mathrm{m}^{3}}\right]$ & $\mathrm{T}\left[{ }^{\circ} \mathrm{C}\right]$ & $\mathrm{RH} \%$ & \# of sets \\
\hline 1 & 08.01 & 9.5 & 77 & -1.5 & 92.3 & 17 \\
2 & 12.01 & 8.0 & 63 & -2.8 & 86.0 & 18 \\
3 & 13.01 & 7.1 & 37.5 & -4.6 & 76.6 & 16 \\
4 & 18.01 & 6.7 & 68 & -12.5 & 58.7 & 19 \\
5 & 03.02 & 7.3 & 60 & -2.1 & 76.3 & 16 \\
6 & 04.02 & 7.1 & 50 & -2.7 & 69.9 & 18 \\
7 & 01.03 & 7.2 & 36 & -1.1 & 72.8 & 11 \\
\hline
\end{tabular}

reduction could be fragmentation of the snow during the tests (Vionnet and others, 2013). This contradicts the results of Schmidt (1981) that the average particle diameter increases with the winds friction velocity. Still we observed an easy entrainment of large particles at low wind speeds on every test day. This may be explained by the fact that large particles initially have more surface area and are therefore more easily entrained. With the given fetch length, the test routine, the duration of the tests and the conditions in the wind tunnel, we expected no significant change in the snow conditions during a test. Particularly from intermediate mass flux strength to high mass flux strengths, little or no diameter reduction was observed. Density changes during erosion have been shown to be small (Sommer and others, 2018) and therefore we assume constant snow density for the surface flux calculation. The surface flux is of particular interest for the comparison of mass flux through surface erosion with the horizontal particle mass flux. Two time series of the surface mass flux signal recorded with the 


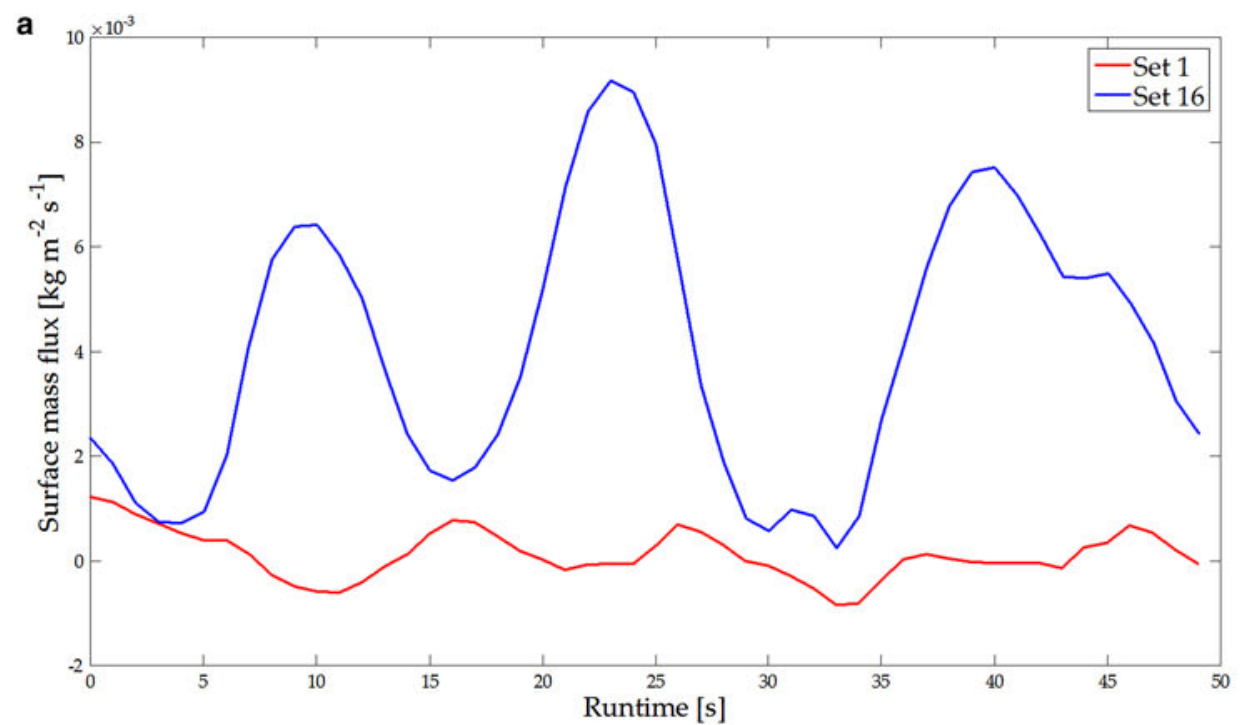

b

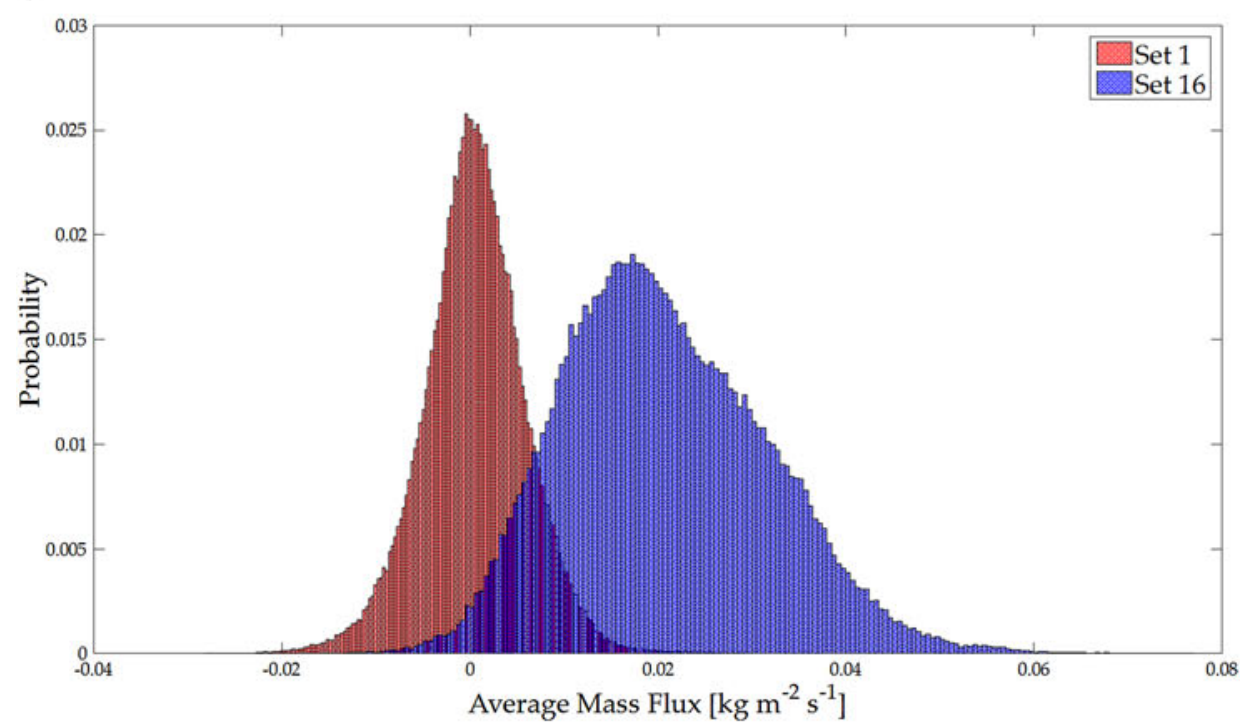

c

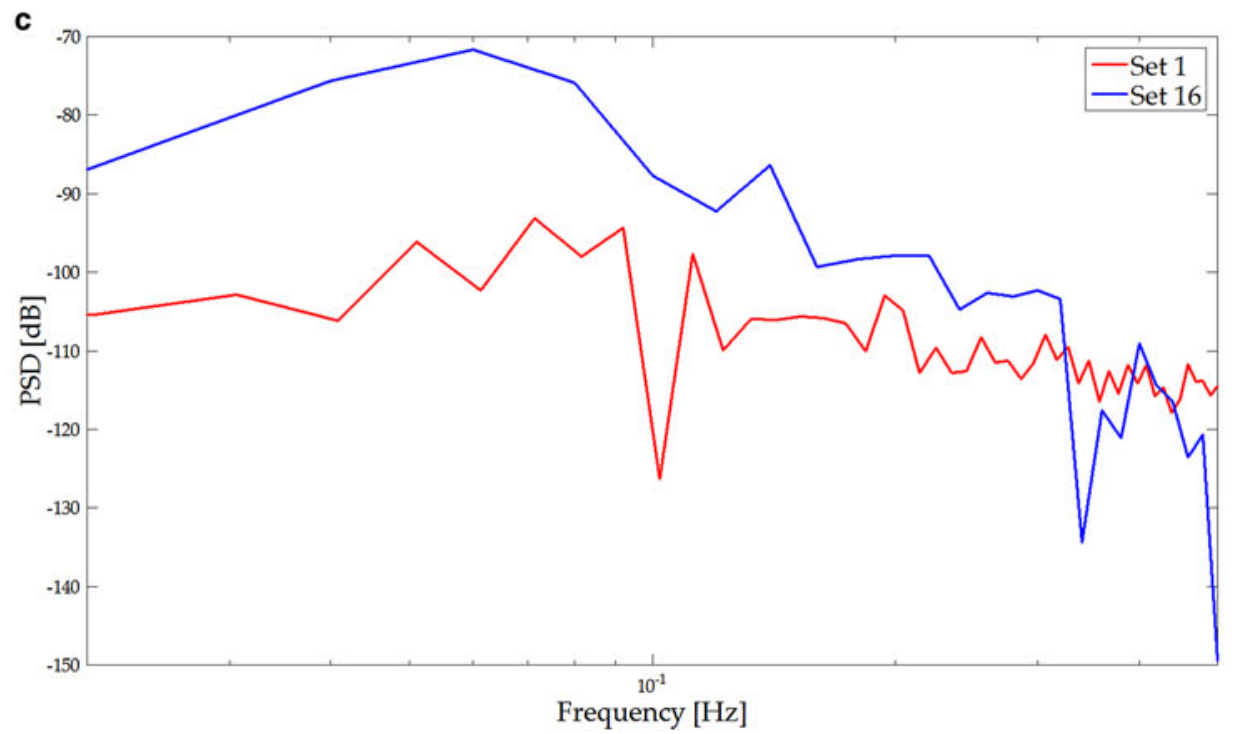

Fig. 5. (a) Example of time series for two sets with different surface mass flux according to (5). Low mass flux (red) and high mass flux (blue). (b) Histogram of the mass flux for the same two sets. The histogram represents all surface mass flux values for each pixel and time step according to(4). (c) Power spectral density (PSD) for the two time series (for the whole frame again). 
Table 2. The table provides more details of the two sets displayed in Figure 5. On test day 1 the threshold wind speed at which the particle mass flux recorded with the SPC started was $t 9.45 \mathrm{~m} \mathrm{~s}^{-1}$. Set 1 shows that the surface mass flux that has initiated before transported particles were visible. The units for $U_{\text {free }}$ are $\mathrm{ms}^{-1}$, for $q_{\mathrm{s}}$ $\mathrm{kgm}^{-2} \mathrm{~s}^{-1}$

\begin{tabular}{lccc}
\hline Set & max. $U_{\text {free }}$ & mean $q_{\mathrm{S}}$ & Colour \\
\hline 1 & 8.01 & $4.5 \mathrm{e}-4$ & red- \\
16 & 15.04 & $2.8 \mathrm{e}-2$ & blue-
\end{tabular}

Kinect device are shown in Fig. 5a. The red line represents a set with low mass flux, the blue line represents a set with high mass flux (see Table 2). The negative values of the mass flux correspond to the accumulation of snow mass, positive mass flux corresponds to erosion. These values in the time series represent the mass flux averaged over the FOV. Higher intermittency in the signal at lower mass fluxes originates from smaller mass flux activity. The red line in Fig. 5a shows a time series of mass flux close to zero. This represents an equilibrium between overall accumulation and erosion in the Kinect's FOV. Although the SPC and the Kinect time series data could be resampled at the same frequency, the processed time series themselves do not correlate well. This is because, the Kinect records temporal dynamics of snow surface erosion, which is not representative of the saltation layer captured by the SPC (refer to Fig. 6). We attribute this to the fact that we averaged the surface mass flux recorded with the Kinect over the whole area of the FOV. Therefore fluctuations in the temporal dynamics of the surface mass flux are smoothed in comparison with the point measurement of mass flux particles in the saltation layer. At the surface, there is not only homogeneous erosion but constant erosion and deposition at different locations such that the mass flux is smoothed. In the case of the

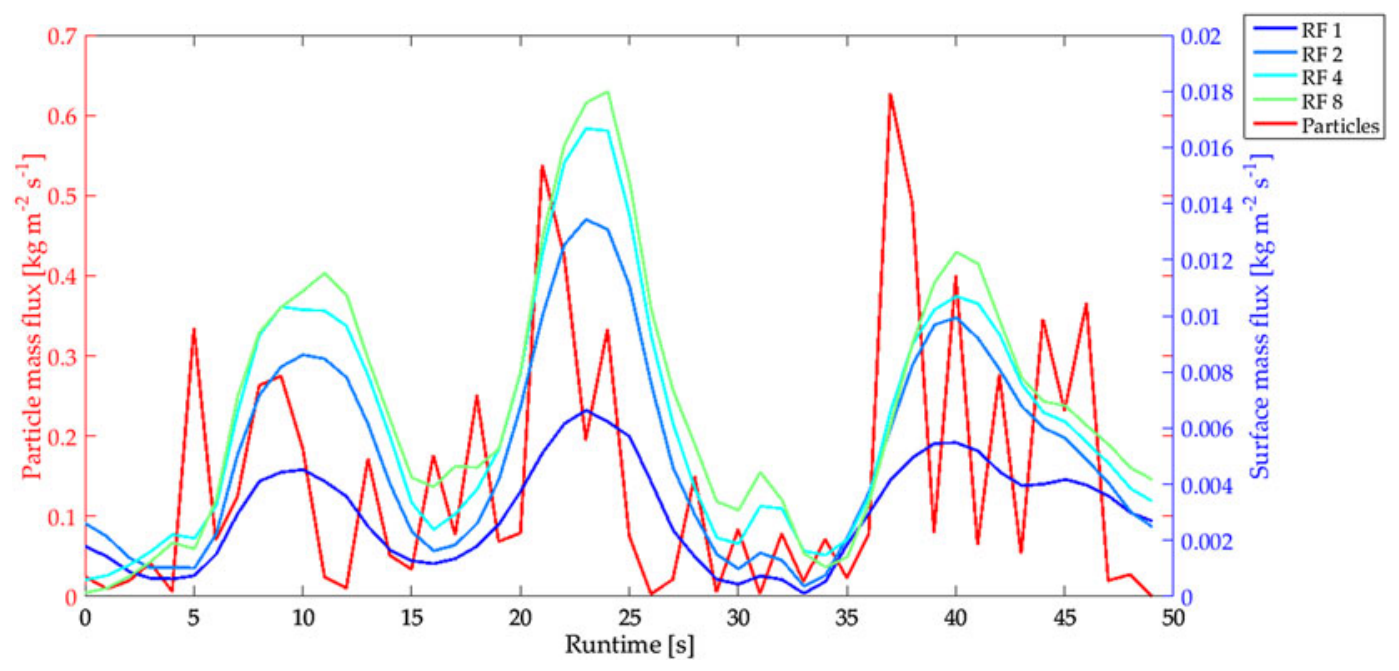

Fig. 6. Mass flux time series of set 16 on test day 1 . The particles mass flux on the left ordinate (red time series) and the surface mass flux on the right ordinate (blue to green time series) for $\operatorname{RF}(1,2,4,8)$ normalized by the corresponding surface area.

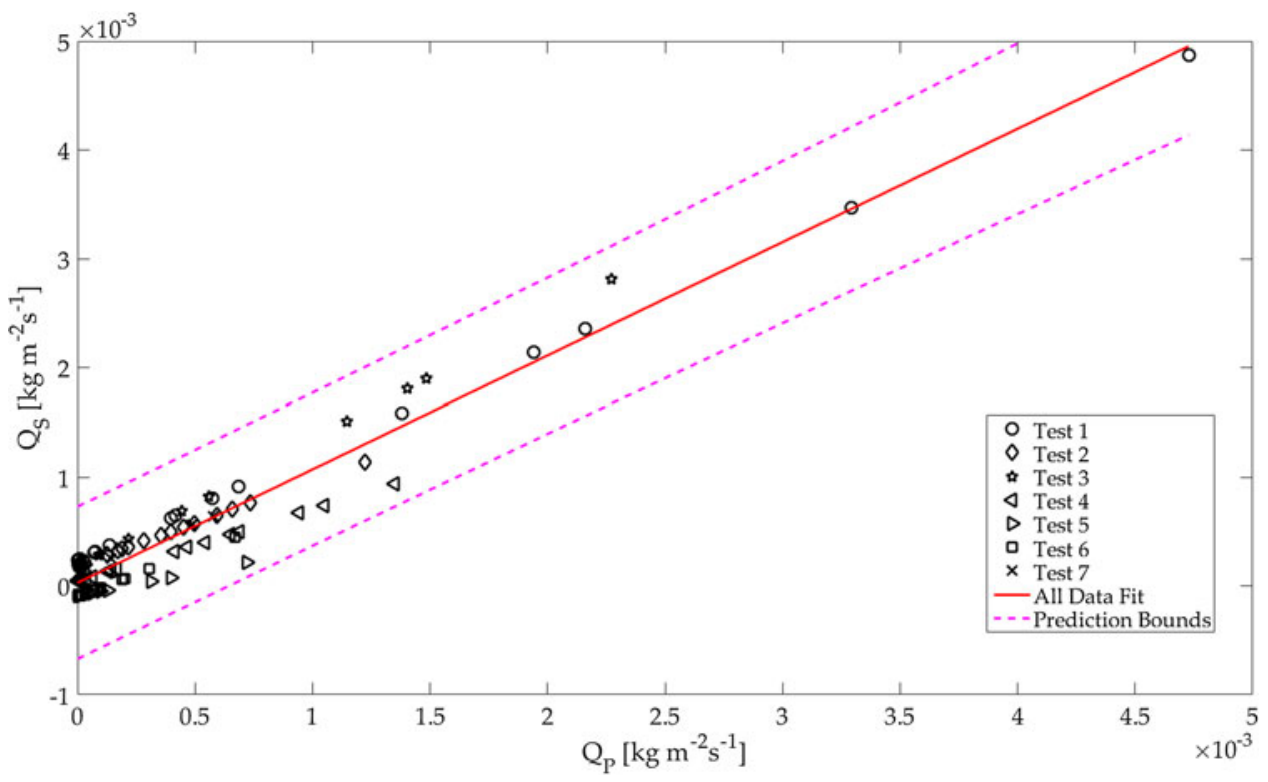

Fig. 7. The red line represents the fit for total mass fluxes $\left(Q_{S}\right.$ vs $Q_{P}$ ) of all 115 sets from 7 test days. The different marker represents different test days. The $95 \%$ confidence interval as the given by the dashed lines. 
Table 3. Correlation of particle mass flux and set-averaged surface mass flux for different RF

\begin{tabular}{|c|c|c|c|c|c|c|}
\hline RF & Event & Event $r^{2}$ & Event $p$ & All $r^{2}$ & All $p$ & Mean side lengths [m \\
\hline \multirow[t]{7}{*}{1} & 1 & 0.759 & $4.06 \times 10^{-4}$ & \multirow[t]{7}{*}{0.572} & \multirow[t]{7}{*}{$2.99 \times 10^{-11}$} & \multirow[t]{7}{*}{$0.57 \times 0.61$} \\
\hline & 2 & 0.887 & $9.42 \times 10^{-7}$ & & & \\
\hline & 3 & 0.931 & $1.72 \times 10^{-7}$ & & & \\
\hline & 4 & 0.469 & $4.27 \times 10^{-2}$ & & & \\
\hline & 5 & 0.343 & 0.194 & & & \\
\hline & 6 & -0.061 & 0.818 & & & \\
\hline & 7 & 0.740 & 0.009 & & & \\
\hline \multirow[t]{7}{*}{2} & 1 & 0.967 & $3.73 \times 10^{-10}$ & \multirow{7}{*}{0.935} & \multirow{7}{*}{$2.60 \times 10^{-52}$} & \multirow{7}{*}{$0.28 \times 0.30$} \\
\hline & 2 & 0.900 & $3.61 \times 10^{-7}$ & & & \\
\hline & 3 & 0.932 & $4.16 \times 10^{-7}$ & & & \\
\hline & 4 & 0.935 & $4.29 \times 10^{-9}$ & & & \\
\hline & 5 & 0.431 & 0.095 & & & \\
\hline & 6 & 0.814 & $1.00 \times 10^{-4}$ & & & \\
\hline & 7 & 0.582 & 0.060 & & & \\
\hline \multirow[t]{7}{*}{4} & 1 & 0.970 & $1.35 \times 10^{-10}$ & \multirow[t]{7}{*}{0.935} & \multirow[t]{7}{*}{$1.17 \times 10^{-54}$} & \multirow[t]{7}{*}{$0.14 \times 0.15$} \\
\hline & 2 & 0.885 & $1.03 \times 10^{-6}$ & & & \\
\hline & 3 & 0.927 & $2.48 \times 10^{-7}$ & & & \\
\hline & 4 & 0.934 & $5.20 \times 10^{-9}$ & & & \\
\hline & 5 & 0.476 & 0.062 & & & \\
\hline & 6 & 0.632 & $6.51 \times 10^{-3}$ & & & \\
\hline & 7 & 0.710 & 0.014 & & & \\
\hline \multirow[t]{7}{*}{8} & 1 & 0.958 & $1.47 \times 10^{-9}$ & \multirow[t]{7}{*}{0.920} & \multirow[t]{7}{*}{$2.56 \times 10^{-47}$} & \multirow[t]{7}{*}{$0.06 \times 0.07$} \\
\hline & 2 & 0.761 & $2.47 \times 10^{-4}$ & & & \\
\hline & 3 & 0.920 & $4.37 \times 10^{-7}$ & & & \\
\hline & 4 & 0.879 & $7.51 \times 10^{-7}$ & & & \\
\hline & 5 & 0.490 & 0.054 & & & \\
\hline & 6 & 0.398 & 0.114 & & & \\
\hline & 7 & 0.667 & 0.025 & & & \\
\hline \multirow[t]{7}{*}{16} & 1 & 0.928 & $7.87 \times 10^{-8}$ & \multirow[t]{7}{*}{0.899} & \multirow[t]{7}{*}{$7.26 \times 10^{-42}$} & \multirow[t]{7}{*}{$0.03 \times 0.04$} \\
\hline & 2 & 0.625 & $5.56 \times 10^{-3}$ & & & \\
\hline & 3 & 0.898 & $2.40 \times 10^{-6}$ & & & \\
\hline & 4 & 0.735 & $3.39 \times 10^{-4}$ & & & \\
\hline & 5 & 0.686 & 0.003 & & & \\
\hline & 6 & 0.477 & 0.053 & & & \\
\hline & 7 & 0.662 & 0.027 & & & \\
\hline
\end{tabular}

horizontal particle mass flux each particle contributes to the mass flux signal independent of the type of surface changes.

Regarding the averaged mass flux from these time series, the two processes correlate well (refer to Fig. 7). Figure 5a also shows that with increasing free-stream velocity the individual peaks of the time series became both larger in amplitude and longer in period. Thus, strong erosion events induce peak mass flux that lasts much longer in comparison with the mass flux peak of smaller erosion events at lower wind speeds. Paterna and others (2016) revealed that in the wind tunnel, strong saltation developed own saltation length scales independent of the turbulent forcing. These events of strong saltation have their highest power at low frequencies leading to longer lasting bursts of snow particles. Also, in their subsequent study, (Paterna and others, 2017) show that in strong saltation peaks of high mass flux persist over a longer time and therefore lead to wider peaks. Figure $5 b$ displays histograms of the mass flux during the two time series from each pixel in the FOV. The results strongly support the previous argument that the equilibrium of erosion and deposition investigated at low mass flux is shifted towards predominantly erosion at high mass flux.

Figure $5 c$ displays the power spectral density (PSD) of the two time series calculated by using MATLAB's pwelch function. The spectral analysis shows differences between equilibrium saltation at low mass flux and erosion dominated saltation, in addition to changes between surface mass flux and particle mass flux. At frequencies close to the sampling frequency $(1 \mathrm{~Hz})$, the PSD of high and low mass flux are similar. At low frequencies (below $0.1 \mathrm{~Hz}$ ), particularly in the case of strong mass flux, the signal contains the strongest power while the power for the low mass flux case is more evenly distributed through the frequencies. This corresponds to what we expected from the observation of wider and longer lasting mass flux peaks of the time series, and is in agreement with the results of Paterna and others (2017).

Figure 6 shows the time series of set 16 (corresponding to the blue lines in the previous figure) observed before (i.e. RF 1) together with the time series of the high mass flux at reduced support areas (RF 2, 4 and 8), as well as the particle mass flux of the SPC for the same set. The magnitude of the surface mass flux increases with decreasing surface area. This increase is based on the fact that the erosion is not uniform in the crosswise direction. Reducing the FOV to the area in the middle of the wind tunnel, areas with less erosion close to the walls are dismissed. Therefore the magnitude increases. This pattern was consistent throughout sets with events of high mass flux on all test days.

This time series further shows that the low-frequency peaks of the surface mass flux correspond well with those of the particle mass flux for all RFs. Furthermore, this is again reflected in the results of Paterna and others (2017) 
Table 4. Correlation of particle mass flux and time-averaged surface mass flux for different RF

\begin{tabular}{|c|c|c|c|c|c|c|}
\hline RF & Event & Event $r^{2}$ & Event $p$ & All $r^{2}$ & All $p$ & Mean side lengths [m] \\
\hline \multirow[t]{7}{*}{1} & 1 & 0.959 & $1.36 \times 10^{-9}$ & \multirow[t]{7}{*}{0.930} & \multirow[t]{7}{*}{$1.59 \times 10^{-50}$} & \multirow[t]{7}{*}{$0.57 \times 0.61$} \\
\hline & 2 & 0.878 & $1.66 \times 10^{-6}$ & & & \\
\hline & 3 & 0.931 & $1.61 \times 10^{-7}$ & & & \\
\hline & 4 & 0.928 & $1.01 \times 10^{-8}$ & & & \\
\hline & 5 & 0.609 & 0.012 & & & \\
\hline & 6 & 0.801 & $5.00 \times 10^{-4}$ & & & \\
\hline & 7 & 0.753 & 0.007 & & & \\
\hline \multirow[t]{7}{*}{2} & 1 & 0.965 & $3.90 \times 10^{-10}$ & \multirow[t]{7}{*}{0.943} & \multirow[t]{7}{*}{$2.14 \times 10^{-55}$} & \multirow[t]{7}{*}{$0.28 \times 0.30$} \\
\hline & 2 & 0.889 & $8.13 \times 10^{-6}$ & & & \\
\hline & 3 & 0.935 & $1.16 \times 10^{-7}$ & & & \\
\hline & 4 & 0.934 & $4.98 \times 10^{-9}$ & & & \\
\hline & 5 & 0.587 & 0.017 & & & \\
\hline & 6 & 0.734 & 0.001 & & & \\
\hline & 7 & 0.699 & 0.017 & & & \\
\hline \multirow{7}{*}{4} & 1 & 0.970 & $1.33 \times 10^{-10}$ & \multirow[t]{7}{*}{0.942} & \multirow[t]{7}{*}{$9.65 \times 10^{-55}$} & \multirow[t]{7}{*}{$0.14 \times 0.15$} \\
\hline & 2 & 0.879 & $1.60 \times 10^{-6}$ & & & \\
\hline & 3 & 0.926 & $2.58 \times 10^{-7}$ & & & \\
\hline & 4 & 0.932 & $6.82 \times 10^{-9}$ & & & \\
\hline & 5 & 0.466 & 0.069 & & & \\
\hline & 6 & 0.582 & 0.014 & & & \\
\hline & 7 & 0.703 & 0.016 & & & \\
\hline \multirow[t]{7}{*}{8} & 1 & 0.959 & $1.38 \times 10^{-9}$ & \multirow{7}{*}{0.921} & \multirow{7}{*}{$1.24 \times 10^{-47}$} & \multirow{7}{*}{$0.06 \times 0.07$} \\
\hline & 2 & 0.773 & $1.69 \times 10^{-4}$ & & & \\
\hline & 3 & 0.920 & $4.72 \times 10^{-7}$ & & & \\
\hline & 4 & 0.880 & $6.96 \times 10^{-7}$ & & & \\
\hline & 5 & 0.480 & 0.060 & & & \\
\hline & 6 & 0.419 & 0.094 & & & \\
\hline & 7 & 0.628 & 0.038 & & & \\
\hline \multirow[t]{7}{*}{16} & 1 & 0.928 & $7.81 \times 10^{-9}$ & \multirow[t]{7}{*}{0.899} & \multirow[t]{7}{*}{$4.52 \times 10^{-42}$} & \multirow[t]{7}{*}{$0.03 \times 0.04$} \\
\hline & 2 & 0.629 & 0.005 & & & \\
\hline & 3 & 0.898 & $2.28 \times 10^{-6}$ & & & \\
\hline & 4 & 0.711 & $6.35 \times 10^{-4}$ & & & \\
\hline & 5 & 0.689 & 0.003 & & & \\
\hline & 6 & 0.700 & 0.002 & & & \\
\hline & 7 & 0.669 & 0.024 & & & \\
\hline
\end{tabular}

Table 5. Values for $\lambda$ given in the literature and the resulting mean $L$-value

\begin{tabular}{lcl}
\hline$\lambda$ & Mean L-value & Source \\
\hline 1.17 & 0.158 & Guala and others (2008) \\
1 & 0.063 & Guala and others (2008) \\
0.8 & 0.036 & Pomeroy and Gray (1990) \\
0.45 & 0.028 & Nishimura and Hunt (2000) \\
0.18 & 0.024 & Guala and others (2008) \\
\hline
\end{tabular}

that strong saltation is characterized by long lasting, wide peaks and that the predominant mechanism of entrainment is by splash-entrainment leading to strong erosion.

\subsection{Set-averaged and time-averaged mass-flux}

As previously stated, we calculated the total, set-averaged surface mass flux $Q_{\mathrm{SB}}$, for each set based on the total mass eroded/deposited within the recording time by subtracting the first surface record in the set from the last of the same set. This way, the temporal information is lost but it becomes possible to compare the integrated particle mass flux profile $\left(Q_{P}\right.$, ref. (8)) to the surface change. To compare
$Q_{P}$ to $Q_{\mathrm{SB}}$, we calculate their correlation for each set within one test day, as well as the overall correlation for all sets with respects to the reduced surface area (refer to the Appendix A, Table 3). In the case of $Q_{\mathrm{SB}}$ for the unreduced surface (i.e. RF $=1$ ), the correlations for the individual events vary largely. Certain events do not correlate (i.e. on test day 6) but some had a very good correlation. Considering all 115 events, the $Q_{\mathrm{SB}}$ does correlate with the averaged particle mass flux $(r=0.572)$. Interestingly, for the case of the reduced support area (RF 2, 4 and 8) the correlation is significantly better (up to $r=0.935$ for RF 2 and 4).

Figure 7 illustrates the correlation analysis between the time-averaged surface mass flux $Q_{\mathrm{S}}$ and the integrated particle mass flux profile $Q_{p}$. Compared with the previous results for the set-averaged surface mass-flux, the timeaveraged surface mass flux correlates significantly better $(r=0.930)$ at the full surface area resolution. The results in the Appendix A and Table 4 again show a higher correlation for the reduced support area (higher than $r=0.94$ for RF 2 and 4). Considering the correlation values and more particularly the significance values for both, the set-averaged and the time-averaged mass flux, it demonstrates that the timeaveraged mass flux is more robust. This also suggests that the sampling frequency needs to be chosen high enough for a comparison of the two mass fluxes. In both cases, $Q_{\mathrm{SB}}$ (Table 3) as well as $Q_{\mathrm{S}}$ (Table 4); the smaller support area 
Table 6. Linear regression coefficients for particle mass flux and setaveraged surface mass flux for different $\lambda$

\begin{tabular}{|c|c|c|c|c|c|}
\hline$\lambda$ & Event & Event $p 1$ & Event $p 2$ & All $p 1$ & All $p 2$ \\
\hline \multirow[t]{7}{*}{1.17} & 1 & 1.012 & $-5.48 \times 10^{-4}$ & \multirow[t]{7}{*}{1.069} & \multirow{7}{*}{$-3.45 \times 10^{-4}$} \\
\hline & 2 & 0.765 & $2.31 \times 10^{-4}$ & & \\
\hline & 3 & 1.226 & $2.23 \times 10^{-4}$ & & \\
\hline & 4 & 1.231 & $-5.71 \times 10^{-4}$ & & \\
\hline & 5 & 4.326 & -0.002 & & \\
\hline & 6 & -0.123 & $-1.38 \times 10^{-4}$ & & \\
\hline & 7 & 1.141 & $1.03 \times 10^{-4}$ & & \\
\hline \multirow[t]{7}{*}{1} & 1 & 0.956 & $-5.47 \times 10^{-4}$ & \multirow[t]{7}{*}{1.010} & \multirow[t]{7}{*}{$-3.40 \times 10^{-4}$} \\
\hline & 2 & 0.729 & $2.33 \times 10^{-4}$ & & \\
\hline & 3 & 1.183 & $2.27 \times 10^{-4}$ & & \\
\hline & 4 & 1.162 & $-5.67 \times 10^{-4}$ & & \\
\hline & 5 & 4.161 & -0.002 & & \\
\hline & 6 & -0.117 & $-1.38 \times 10^{-4}$ & & \\
\hline & 7 & 1.117 & $1.04 \times 10^{-4}$ & & \\
\hline \multirow[t]{7}{*}{0.8} & 1 & 0.886 & $-5.48 \times 10^{-4}$ & \multirow[t]{7}{*}{0.935} & \multirow[t]{7}{*}{$-3.37 \times 10^{-4}$} \\
\hline & 2 & 0.675 & $2.35 \times 10^{-4}$ & & \\
\hline & 3 & 1.106 & $2.30 \times 10^{-4}$ & & \\
\hline & 4 & 1.070 & $-5.64 \times 10^{-4}$ & & \\
\hline & 5 & 3.875 & -0.002 & & \\
\hline & 6 & -0.109 & $-1.38 \times 10^{-4}$ & & \\
\hline & 7 & 1.058 & $1.05 \times 10^{-4}$ & & \\
\hline \multirow[t]{7}{*}{0.45} & 1 & 0.754 & $-5.53 \times 10^{-4}$ & \multirow[t]{7}{*}{0.792} & \multirow[t]{7}{*}{$-3.45 \times 10^{-4}$} \\
\hline & 2 & 0.554 & $2.35 \times 10^{-4}$ & & \\
\hline & 3 & 0.903 & $2.32 \times 10^{-4}$ & & \\
\hline & 4 & 0.888 & $-5.64 \times 10^{-4}$ & & \\
\hline & 5 & 3.155 & -0.002 & & \\
\hline & 6 & -0.092 & $-1.37 \times 10^{-4}$ & & \\
\hline & 7 & 0.868 & $1.06 \times 10^{-4}$ & & \\
\hline \multirow[t]{7}{*}{0.18} & 1 & 0.648 & $-5.63 \times 10^{-4}$ & \multirow[t]{7}{*}{0.676} & \multirow[t]{7}{*}{$-3.64 \times 10^{-4}$} \\
\hline & 2 & 0.446 & $2.32 \times 10^{-4}$ & & \\
\hline & 3 & 0.704 & $2.27 \times 10^{-4}$ & & \\
\hline & 4 & 0.738 & $-5.70 \times 10^{-4}$ & & \\
\hline & 5 & 2.473 & -0.002 & & \\
\hline & 6 & -0.078 & $-1.37 \times 10^{-4}$ & & \\
\hline & 7 & 0.662 & $1.05 \times 10^{-4}$ & & \\
\hline
\end{tabular}

(i.e. $\mathrm{RF}=2$ and $\mathrm{RF}=4$ ) gives a better correlation. This is because in the case of the reduced surface area, the focus is set on the surface just in front of the particle counter. Another result visible in Figure 7 is that in the case of timeaveraged surface mass flux $\left(Q_{S}\right.$ on the $y$-axis), the mass flux is near zero for most sets with low and intermediate mass flux strength. This suggests that there is an equilibrium between erosion and deposition similar to what was presented in Figure 5b. This equilibrium shifts towards erosion only $\left(Q_{S}>0\right)$ in the case of stronger mass flux. The parametric study on the saltation-length-scale parameter $\lambda$, showed the results were proportional, and therefore the correlation was not influenced significantly. A more interesting observation within that study is the results of linear regressions for the particle mass flux and surface erosion

$$
Q_{\mathrm{S}}=p 1 Q_{\mathrm{P}}+p 2
$$

The overview over the results of the regression coefficients $p 1$ and $p 2$ are displayed in the Appendix B, Table 6 for the set-averaged mass flux and Table 7 for the time-averaged mass flux. Looking at the regression coefficient over all events $(A / / p 1)$, we find that in the case of set-averaged mass flux, $p 1$ increases with an increasing $\lambda$ from 0.676 to 1.069. First, this means that the estimated mass change from the integrated particle mass flux is slightly larger or
Table 7. Linear regression coefficients for particle mass flux and time-averaged surface mass flux for different $\lambda$

\begin{tabular}{|c|c|c|c|c|c|}
\hline$\lambda$ & Event & Event $p 1$ & Event $p 2$ & All $p 1$ & All $p 2$ \\
\hline \multirow[t]{7}{*}{1.17} & 1 & 0.772 & $1.88 \times 10^{-3}$ & \multirow[t]{7}{*}{0.966} & \multirow[t]{7}{*}{$2.93 \times 10^{-5}$} \\
\hline & 2 & 0.723 & $1.47 \times 10^{-3}$ & & \\
\hline & 3 & 1.139 & $1.16 \times 10^{-3}$ & & \\
\hline & 4 & 0.591 & $2.23 \times 10^{-4}$ & & \\
\hline & 5 & 0.411 & -0.003 & & \\
\hline & 6 & 0.662 & -0.002 & & \\
\hline & 7 & 0.914 & $1.13 \times 10^{-4}$ & & \\
\hline \multirow[t]{7}{*}{1} & 1 & 0.730 & $2.62 \times 10^{-4}$ & \multirow[t]{7}{*}{0.970} & \multirow[t]{7}{*}{$1.24 \times 10^{-5}$} \\
\hline & 2 & 0.689 & $1.97 \times 10^{-4}$ & & \\
\hline & 3 & 1.100 & $1.82 \times 10^{-4}$ & & \\
\hline & 4 & 0.559 & $4.32 \times 10^{-5}$ & & \\
\hline & 5 & 0.392 & $-9.41 \times 10^{-5}$ & & \\
\hline & 6 & 0.626 & $-8.86 \times 10^{-4}$ & & \\
\hline & 7 & 0.895 & $1.14 \times 10^{-4}$ & & \\
\hline \multirow[t]{7}{*}{0.8} & 1 & 0.677 & $2.61 \times 10^{-4}$ & \multirow[t]{7}{*}{0.898} & \multirow[t]{7}{*}{$1.42 \times 10^{-5}$} \\
\hline & 2 & 0.638 & $1.98 \times 10^{-4}$ & & \\
\hline & 3 & 1.029 & $1.85 \times 10^{-3}$ & & \\
\hline & 4 & 0.516 & $4.43 \times 10^{-5}$ & & \\
\hline & 5 & 0.363 & $-9.35 \times 10^{-5}$ & & \\
\hline & 6 & 0.578 & $-8.85 \times 10^{-5}$ & & \\
\hline & 7 & 0.848 & $1.15 \times 10^{-4}$ & & \\
\hline \multirow[t]{7}{*}{0.45} & 1 & 0.577 & $2.55 \times 10^{-4}$ & \multirow[t]{7}{*}{0.747} & \multirow[t]{7}{*}{$1.30 \times 10^{-5}$} \\
\hline & 2 & 0.524 & $1.99 \times 10^{-4}$ & & \\
\hline & 3 & 0.840 & $1.87 \times 10^{-4}$ & & \\
\hline & 4 & 0.426 & $4.434 \times 10^{-5}$ & & \\
\hline & 5 & 0.295 & $-9.35 \times 10^{-5}$ & & \\
\hline & 6 & 0.488 & $-8.93 \times 10^{-5}$ & & \\
\hline & 7 & 0.696 & $1.15 \times 10^{-4}$ & & \\
\hline \multirow[t]{7}{*}{0.18} & 1 & 0.497 & $2.46 \times 10^{-4}$ & \multirow[t]{7}{*}{0.612} & \multirow[t]{7}{*}{$7.52 \times 10^{-6}$} \\
\hline & 2 & 0.421 & $1.99 \times 10^{-4}$ & & \\
\hline & 3 & 0.655 & $1.82 \times 10^{-4}$ & & \\
\hline & 4 & 0.350 & $4.51 \times 10^{-5}$ & & \\
\hline & 5 & 0.235 & $-9.38 \times 10^{-5}$ & & \\
\hline & 6 & 0.414 & $-9.13 \times 10^{-5}$ & & \\
\hline & 7 & 0.531 & $1.15 \times 10^{-4}$ & & \\
\hline
\end{tabular}

closely the same as the set-averaged mass flux at the surface. Second, that for a $\lambda$ with $p 1$ close to one, the integrated particle mass flux is a good estimator of the total change at the surface. Having the best fit at $\lambda=1$ means that for the set-averaged mass-flux, the mass flux profile is confined near to the surface. Notably, in the case of $Q_{\mathrm{SB}}$, the variability in the regression coefficient is relatively high for $\lambda$ close to one and becomes smaller with a smaller $\lambda$. When considering the time-averaged surface mass flux $Q_{\mathrm{S}}$, the relation is very similar ( $p 1$ ranges between 0.612 and $0.970)$, meaning that the time-averaged surface mass flux is slightly smaller than the integrated particle mass flux profile for all five values of $\lambda$. Again, the best fit is achieved with $\lambda=1$. This means that by assuming the mass transport closely confined to the surface, the integrated particle mass flux profile best represents the change of mass by erosion and deposition. By comparing the absolute numbers for integrated particle mass flux for $\lambda=0.18$ and $\lambda=1.17$ we show that the latter is significantly smaller. This means in the case of our studies, assuming a high saltation layer overestimates the total integrated particle mass-flux.

\subsection{Spectral distribution}

As stated at the beginning of this section, we use the mass flux power spectra to characterize differences between surface and particle mass fluxes. We have already demonstrated 

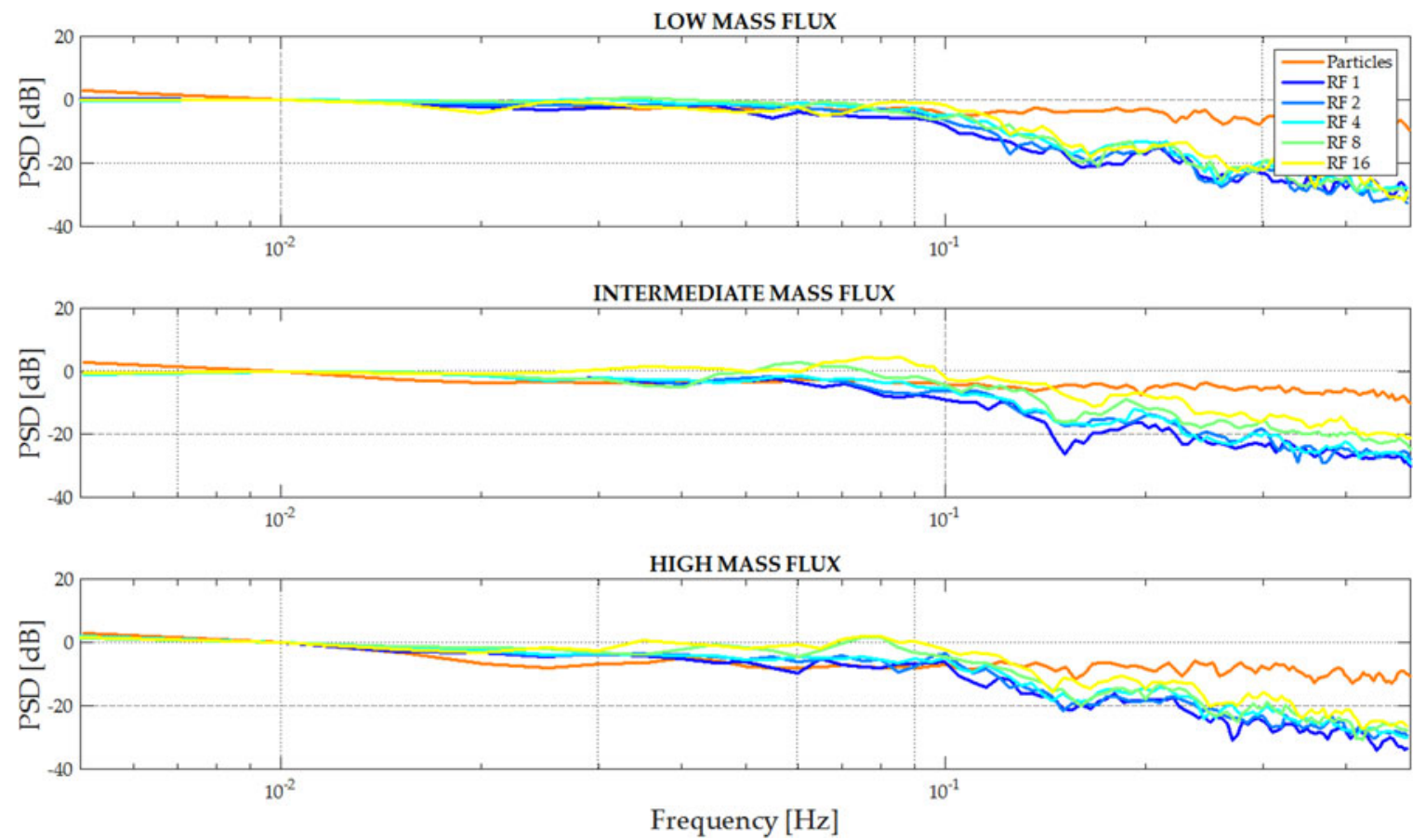

Fig. 8. PSD for different RF.

with the example in the introduction that there is a difference in the spectrum between high and low mass-flux. Figure 8 shows the spectra over all events for the different RF. All spectra are scaled to their value at $0.01 \mathrm{~Hz}$ and averaged in frequency classes of $0.05 \mathrm{~Hz}$. For the subsequent analysis and presentation the sets were separated in low, intermediate and high mass flux based on the time-averaged mass flux strength on the individual test day. Additionally to the spectrum of the surface mass-flux, the spectrum of the particle mass flux was added. It is clear that in the case of the particle mass-flux, the power is evenly distributed through the

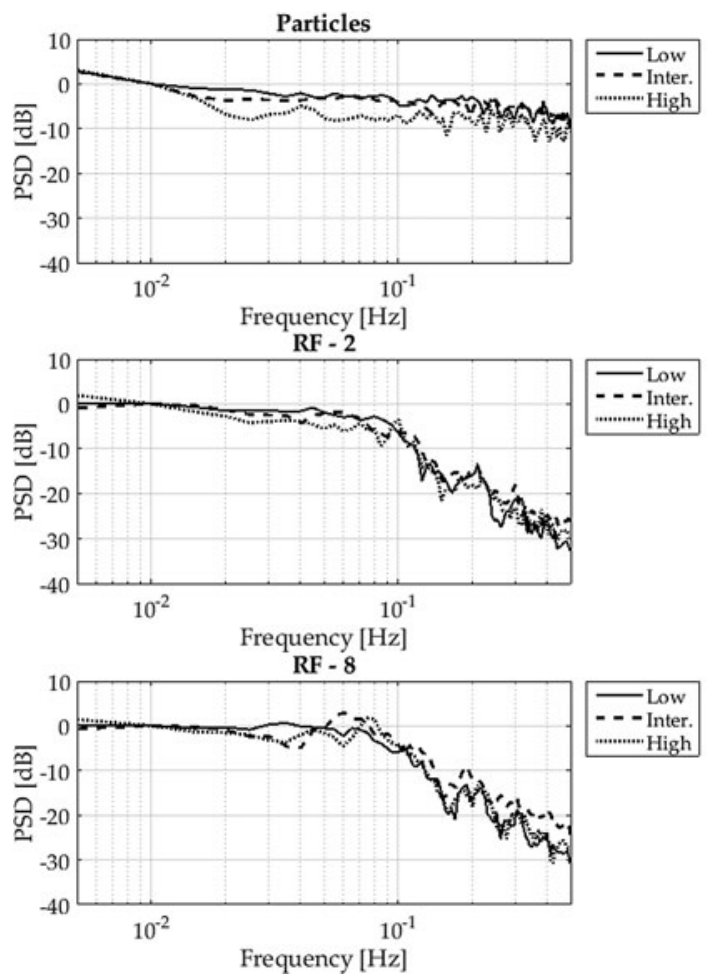

spectra. However, the surface mass flux has its largest power at low frequencies, which decreases rapidly towards higher frequencies. Another interesting result is that for the low mass flux, there seems to be no relevant difference in the spectra dependent on the RF. For the intermediate mass flux and certainly for the high mass flux, in the region between $3 \times 10^{-1}$ and $10^{-1} \mathrm{~Hz}$, the power increases with a decreasing support area. We explain this behaviour based on the fact that for low mass fluxes, the differences between the individual test days are not as large as for the high mass fluxes. Additionally, for low mass flux strengths,

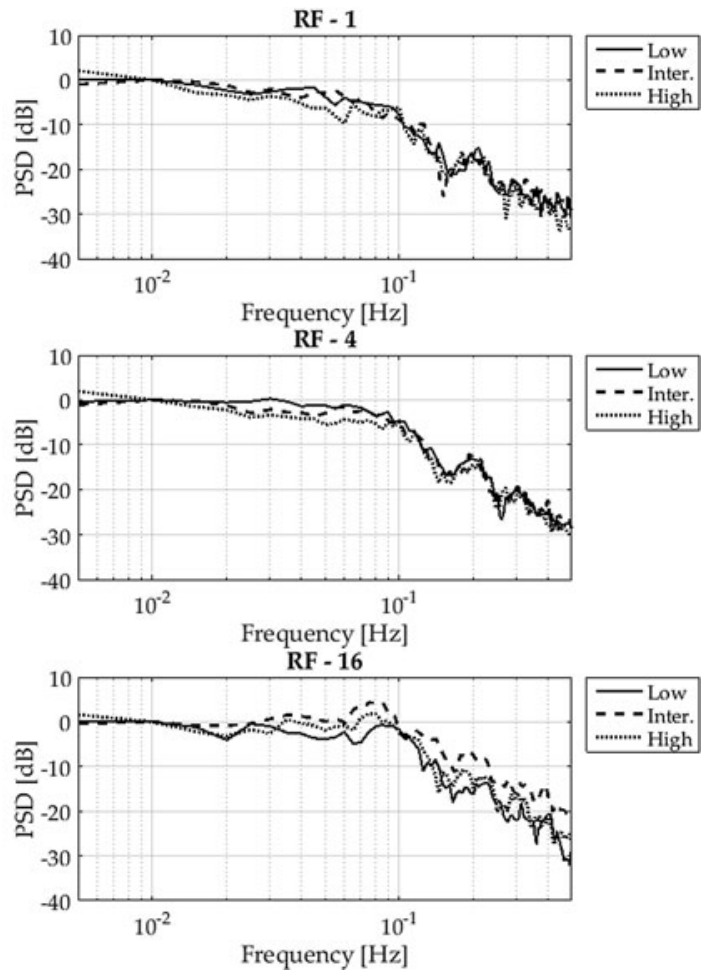

Fig. 9. PSD of high, intermediate and low mass flux, for individual surface RF. 

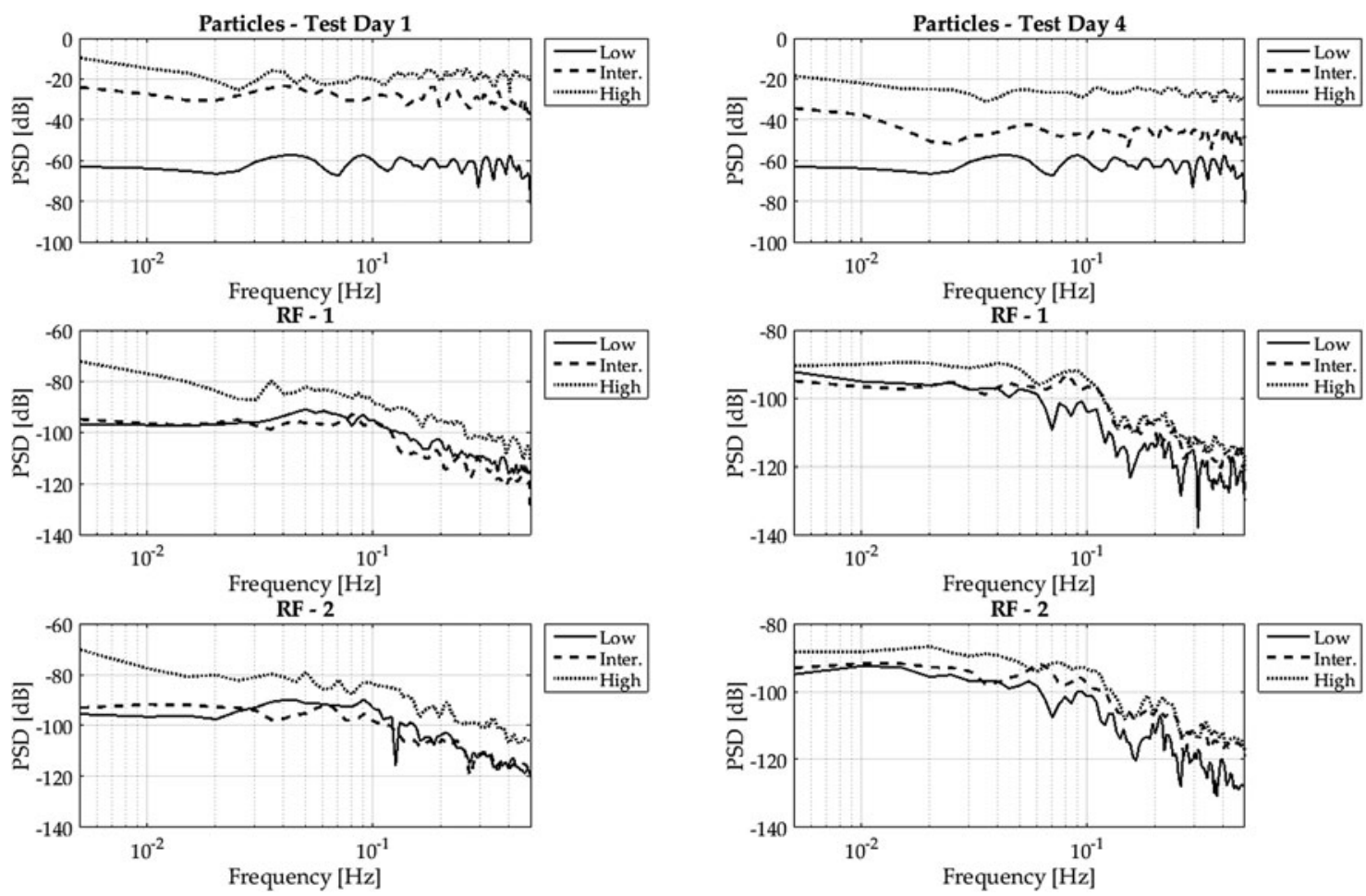

Fig. 10. Unnormalized PSD for high, intermediate and low mass flux for test day 1 (left column) and test day 4 (right column) for the particle mass flux and RF 1 and 2 .

we experienced a more homogeneous surface change in the crosswise direction. The higher the wind speeds became, the higher the variability between the RF. A portion of this variability may be influenced by the tunnel sidewalls, although a quantification of this influence was not possible. This crosswise variability is also reflected in the differences of the spectra at depending on the mass flux strength as well as for the support area.

Figure 9 displays the spectra based on the mass flux for the individual surface RF as well as the particle mass flux for all seven test days. As in the previous figure, the PSD for the particle flux is evenly distributed through all frequencies, independent of the mass flux strength. Observing the PSD as a function of the size of the support area, we find that with increasing surface area the power is more evenly distributed in the spectra. That is at RF 1, the gradient of the slope at a frequency of $\sim 10^{-1}$ is relatively smooth and becomes sharper with increasing RF. We hypothesize that the smoother change at larger observation areas (i.e. RF 1) is because over larger areas, changes due to small-scale events are more smoothed in comparison with smaller observation areas. Unlike the small-scale events at higher frequencies, the slow, larger-scale events of the erosion/deposition occur over the whole FOV and are less dependent on the RF. Therefore, the slow, large events of the erosion/deposition dynamics are more dominant in the spectra.

Figure 10 displays the un-normalized spectra for two different test days. On Test day 1, we experienced the highest mass flux. On test day 4, the relative mass flux strength was much smaller. Again the spectra of the particle mass flux look very much alike from their shape. But other than in Figure 8, the unnormalized PSD shows a significant separation of the power dependent on the mass flux strength. Interestingly, for both test days, the power spectra are much closer together for surface mass flux. Still the power is highest for high mass flux, but the gap between high and low mass flux cases is much smaller, particularly at higher frequencies. For the two test days, if the support area is reduced by a factor two, it does not show a significant change in the shape of the PSD. Furthermore, there is no significant separation of the spectra for the intermediate and low mass flux case. Only the shape of the high mass flux case looks different, particularly for test day 1 (which had the strongest mass flux in absolute numbers over all experiments) at low frequencies. This is again in line with the results of Paterna and others (2017) who demonstrate how the duration of events of strong erosion are longer compared with weaker erosion.

\section{CONCLUSIONS}

The present study establishes a link between the dynamics of erosion and deposition of snow during snow drifting and blowing at the surface and the snow particles recorded in the saltation layer, applying a newly developed Microsoft Kinect measurement system adapted to a wind tunnel. For the first time, it has been possible to observe and record snow erosion and deposition with a high temporal and spatial resolution. Additionally, it has been possible to measure a quantitative set-averaged mass flux of the total snow mass eroded. A large proportion of the sources of snow transported in the saltation layer can be observed by recording the particle-induced change in the snow surface due to erosion and deposition. Although the accuracy of the Microsoft Kinect is not sufficient to record individual particles, it is possible to record the sum contribution of all particle surface interaction such as deposition at the surface, aerodynamical entrainement or entrainement of particles on the surface due to 'splash-entrainement' from impacting particles. During the different experiments a representative variety of snow and environmental conditions were experienced. For the seven test days the threshold wind speed, 
maximum particle mass flux and snow density were different (see Table 1). We observed equilibrium between erosion and deposition at lower mass fluxes which shifts to predominantly erosion for higher mass fluxes. This study also shows that despite the fact that the temporal dynamics of the mass flux derived from the surface change was significantly different from the particle mass flux in the saltation layer; their average mass flux correlates very well, particularly in case of test day with strong erosion. The correlation can be improved further by reducing the observed snow surface and focussing to a smaller area in front of the SPC. The parametric study for the saltation length scale demonstrated that the best fit between surface mass flux and particle mass flux is achieved for a saltation-length-scale parameter $\lambda$ close to 1 , which translates to a saltation layer that is confined near the surface. The study highlights significant differences in the mass flux between particle saltation and snow surface erosion. The latter has the most power at low frequencies, particularly when considering smaller areas, while the power of the particle mass flux is distributed more evenly through the spectra of the observed frequencies. Despite differences in the characteristic mass flux temporal dynamics, the high correlation suggests that changes of the snow surface are well represented in SPC recordings if long averaging windows are considered. We can therefore conclude that the integrated particles mass flux signal in the saltation layer can be used to quantify the mass eroded on the surface. Furthermore, this would permit estimates of the total mass change to be made from SPC measurements of the particle mass flux only. Readers should consider that this study was performed in a wind tunnel with constant wind speed, which allowed us to control the erosion in the experiments. The limited snow fetch available for snow saltation, an inherent limitation of any wind tunnel experiment, implies that while equilibrium saltation is observed at low mass-flux, at higher mass flux erosion tends to dominate. If a similar study were performed in the field, a much more complex situation would present itself and the results would likewise be influenced by the formation of snow bed forms. It would provide the opportunity to test our results against saltation with a longer flux footprint and under variable wind speeds.

\section{ACKNOWLEDGMENTS}

We wish to express our acknowledgment to the Swiss National Science Foundation (SNF) for funding this research (R grant No. 200021-147184) and the wind tunnel facility (REquip grant No. 2160-060998) as well as to James Glover for his effortin writing this article.

\section{REFERENCES}

Bagnold RA (1937) The transport of sand by wind. Geogr. J., 89(5), 409-438, 14754959

Bagnold RA (1941) The physics of wind blown sand and desert dunes. Methuen, London, 265(10), 256 pp.

Clifton A, Rüedi JD and Lehning M (2006) Snow saltation threshold measurements in a drifting-snow wind tunnel. J. Glaciol., 52 (179), 585-596 (doi: 10.3189/172756506781828430)

Comola F and Lehning M (2017) Energy and momentum conserving model of splash entrainment in sand and snow saltation. Geophys. Res. Lett. (doi: 10.1002/2016GL071822), 2016GL071822.

Dolatabadi E, Taati B and Mihailidis A (2014) Vision-based approach for long-term mobility monitoring: single case study following total hip replacement. J. Rehabil. Res. Dev., 51(7), 1165-1176 (doi: 10.1682/jrrd.2013.12.0263)

Dong Z and Qian G (2007) Characterizing the height profile of the flux of wind-eroded sediment. Environmental Geology, 51(5), 835-845 (doi: 10.1007/s00254-006-0363-5)

Dong Z, Liu X, Wang H, Zhao A and Wang X (2003) The flux profile of a blowing sand cloud: a wind tunnel investigation. Geomorphology, 49(3-4), 219-230 (doi: http://dx.doi.org/10. 1016/S0169-555X(02)00170-8)

Doorschot JJ, Lehning M and Vrouwe A (2004) Field measurements of snow-drift threshold and mass fluxes, and related model simulations. Boundary. Layer. Meteorol., 113(3), 347-368 (doi: 10.1007/s10546-004-8659-z)

Essmaeel K, Gallo L, Damiani E, De Pietro G and Dipanda A (2012) Temporal denoising of kinect depth data. In Signal Image Technology and Internet Based Systems (SITIS), 2012 Eighth International Conference on, 47-52, IEEE (doi: 10.1109/ SITIS.2012.18).

Essmaeel K, Gallo L, Damiani E, De Pietro G and Dipanda A (2014) Comparative evaluation of methods for filtering kinect depth data. Multimed. Tools. Appl., 74(17), 1-24 (doi: 10.1007/ s11042-014-1982-6)

Filhol S and Sturm M (2015) Snow bedforms: A review, new data, and a formation model. J. Geophys. Res.: Earth Surf., 120(9), 1645-1669 (doi: 10.1002/2015JF003529), 2015JF003529

Gillette DA and Walker TR (1977) Characteristics of airborne particles produced by wind erosion of sandy soil, high plains of west Texas. Soil Science 123(2), 97-110.

Gordon M and Taylor PA (2009) Measurements of blowing snow, part i: particle shape, size distribution, velocity, and number flux at Churchill, Manitoba, Canada. Cold. Reg. Sci. Technol., 55(1), 63-74 (doi: 10.1016/j.coldregions. 2008.05.001)

Gordon M, Savelyev S and Taylor PA (2009) Measurements of blowing snow, part ii: mass and number density profiles and saltation height at Franklin bay, nwt, Canada. Cold. Reg. Sci. Technol., 55(1), 75-85 (doi: 10.1016/j.coldregions.2008. 07.001)

Gromke C, Manes C, Walter B, Lehning M and Guala M (2011) Aerodynamic roughness length of fresh snow. Boundary. Layer. Meteorol., 141(1), 21-34 (doi: 10.1007/s10546-011-9623-3)

Gromke C, Horender S, Walter B and Lehning M (2014) Snow particle characteristics in the saltation layer. J. Glaciol., $60(221)$, 431-439 (doi: 10.3189/2014JoG13J079)

Groot Zwaaftink C and 6 others (2013) Event-driven deposition of snow on the Antarctic plateau: analyzing field measurements with snowpack. Cryosphere, 7(1), 333-347 (doi: 10.5194/tc-7333-2013)

Grünewald T, Schirmer M, Mott R and Lehning M (2010) Spatial and temporal variability of snow depth and ablation rates in a small mountain catchment. Cryosphere, 4(2), 215-225 (doi: 10.5194/ tc-4-215-2010)

Guala M, Manes C, Clifton A and Lehning M (2008) On the saltation of fresh snow in a wind tunnel: profile characterization and single particle statistics. J. Geophys. Res.: Earth Surf. (2003-2012), 113 (F3) (doi: 10.1029/2007JF000975)

Kawamura R (1948) Sand movement by wind. Kagaku, 18(11), 24-30

Kawamura R (1951) Study on sand movement by wind(relationship between sand flow and wind friction, and vertical density distribution of sand). Tokyo Daigaku Rikogaku Kenkyusho Hokoku, (Tokyo), 5(3), 95-112

Kok JF, Parteli EJ, Michaels TI and Karam DB (2012) The physics of wind-blown sand and dust. Rep. Prog. Phys., 75(10), 106901.

Mankoff KD and Russo TA (2012) The kinect: A low-cost, highresolution, short-range 3d camera. Earth. Surf. Process. Landf., 38(9), 926-936

Meister R (1987) Wind systems and snow transport in alpine topography. IAHS Publ, 162, 265-279

Meister R (1988) Influence of strong winds on snow distribution and avalanche activity. Ann. Glaciol., 13, 195-201 
Michaux JL, Naaim-Bouvet F, Naaim M, Lehning M and Guyomarc'h G (2002) Effect of unsteady wind on drifting snow: first investigations. Natural Hazards and Earth System Science, 2(3/4), 129-136

Miller RL and 10 others (2006) Mineral dust aerosols in the NASA Goddard institute for space sciences model atmospheric general circulation model. J Geophys Res Atmos., 111(D6) (doi: 10.1029/2005JD005796), d06208.

Naaim-Bouvet F, Bellot H and Naaim M (2010) Back analysis of drifting-snow measurements over an instrumented mountainous site. Ann. Glaciol., 51, 207-217 (doi: 10.3189/1727564 10791386661)

Naaim-Bouvet F, Naaim M, Bellot H and Nishimura K (2011) Wind and drifting-snow gust factor in an alpine context. Ann. Glaciol., 52(58), 223-230 (doi: 10.3189/172756411797252112)

Nalpanis P, Hunt JCR and Barrett CF (1993) Saltating particles over flat beds. J. Fluid. Mech., 251, 661-685 (doi: 10.1017/ S0022112093003568)

Nicholson LI, Pętlicki M, Partan B and MacDonell S (2016) 3-d surface properties of glacier penitentes over an ablation season, measured using a microsoft xbox kinect. Cryosphere, 10(5), 1897-1913

Nishimura K and Hunt JCR (2000) Saltation and incipient suspension above a flat particle bed below a turbulent boundary layer. J. Fluid. Mech., 417, 77-102 (doi: 10.1017/S0022112000001014)

Nishimura K and Nemoto M (2005) Blowing snow at Mizuho station, Antarctica. Philosophical Transactions of the Royal Society A: Mathematical, Physical and Engineering Sciences, 363(1832), 1647-1662 (doi: 10.1098/rsta.2005.1599)

Nishimura K, Sugiura K, Nemoto M and Maeno N (1998) Measurements and numerical simulations of snow-particle saltation. Ann. Glaciol., 26, 184-190

Owen PR (1964) Saltation of uniform grains in air. J. Fluid Mech., 20 (2), 225-242

Paterna E, Crivelli P and Lehning M (2016) Decoupling of mass flux and turbulent wind fluctuations in drifting snow. Geophys. Res. Lett., 43, 4441-4447 (doi: 10.1002/2016 GL068171), 2016 GL068171.

Paterna E, Crivelli P and Lehning M (2017) Wind tunnel observations of weak and strong snow saltation dynamics. J. Geophys. Res.: Earth Surf., 122, 1589-1604

Pomeroy J (1991) Transport and sublimation of snow in windscoured alpine terrain. Snow, Hydrology and Forests in High Alpine Areas (Proceedings of the Vienna Symposium, August 1991). IAHS Publ. no. 205, 1991

Pomeroy JW and Gray DM (1990) Saltation of snow. Water. Resour. Res., 26(7), 1583-1594 (doi: 10.1029/WR026i007p01583)

Prochazka A and 5 others (2016) Extraction of breathing features using ms kinect for sleep stage detection. Signal. Image. Video. Process., 10(7), 1279-1286 (doi: 10.1007/s11760-016-0897-2)

Rasmussen SMWB, KR (1985) Measurement of saltation and wind strength on beaches. Mem. 8. University of Aarhus, Denmark, 2, 301-325

Schmidt R (1980) Threshold wind-speeds and elastic impact in snow transport. J. Glaciol., 26, 453-467.

Schmidt R (1981) Estimates of threshold windspeed from particle sizes in blowing snow. Cold. Reg. Sci. Technol., 4(3), 187-193 (doi: https://doi.org/10.1016/0165-232X(81)90003-3)

Schmidt R (1982) Properties of blowing snow. Rev. Geophys., 20(1), $39-44$.
Schmidt R, Meister R and Gubler H (1984) Comparison of snow drifting measurements at an alpine ridge crest. Cold. Reg. Sci. Technol., 9(2), 131-141 (doi: http://dx.doi.org/10.1016/0165232X(84)90005-3)

Sommer CG, Lehning M and Fierz C (2018) Wind tunnel experiments: influence of erosion and deposition on wind-packing of new snow. Frontiers in Earth Science, 6, 4 (doi: 10.3389/ feart.2018.00004)

Sugiura K, Nishimura K, Maeno N and Kimura T (1998) Measurements of snow mass flux and transport rate at different particle diameters in drifting snow. Cold. Reg. Sci. Technol., 27 (2), 83-89 (doi: 10.1016/S0165-232X(98)00002-0)

Trujillo E, Ramrez JA and Elder KJ (2007) Topographic, meteorologic, and canopy controls on the scaling characteristics of the spatial distribution of snow depth fields. Water. Resour. Res., 43(7) (doi: 10.1029/2006WR005317), w07409.

Trujillo E, Leonard K, Maksym T and Lehning M (2016) Changes in snow distribution and surface topography following a snowstorm on Antarctic sea ice. J. Geophys. Res.: Earth Surf., 121(11), 21722191 (doi: 10.1002/2016JF003893), 2016JF003893

Vionnet $V$ and 7 others (2013) Occurrence of blowing snow events at an alpine site over a 10-year period: Observations and modelling. Advances in Water Resources, 55, 53-63 (doi: http://doi.org/ 10.1016/j.advwatres.2012.05.004), snow-Atmosphere Interactions and Hydrological Consequences.

Walter B, Horender S, Voegeli C and Lehning M (2014) Experimental assessment of Owen's second hypothesis on surface shear stress induced by a fluid during sediment saltation. Geophys. Res. Lett., 41(17), 6298-6305 (doi: 10.1002/2014GL061069)

Yavsan E and Ucar A (2016) Gesture imitation and recognition using kinect sensor and extreme learning machines. Measurement: Journal of the International Measurement Confederation, 94, 852-861 (doi: 10.1016/j.measurement.2016.09.026)

Zender CS, Newman D and Torres O (2003) Spatial heterogeneity in aeolian erodibility: Uniform, topographic, geomorphic, and hydrologic hypotheses. J Geophys Res Atmos., 108(D17) (doi: 10.1029/2002JD003039), 4543.

\section{APPENDIX A. SURFACE AREA REDUCTION}

For each values RF, both side lengths of the observation area were divided through the corresponding number. Therefore the value of RF represent the power of 2 used to reduce the observed surface area of the Kinect. That is $R F=2$ means $1 / 2$ of the full side length in streamwise direction and $1 / 2$ of the full side length in crosswise direction. This results in $1 / 4$ of the full surface area used for the mass flux calculation.

\section{APPENDIX B. SALTATION LENGTH SCALE}

The saltation length scale $L=\left(u_{*}^{2}\right) /(\lambda g)$ was introduced earlier in Section 2.1 for the calculation of the particle mass flux profile in the saltation layer. The literature stated different values for the constant parameter $\lambda$. Therefore we performed a sensitivity analysis with based on some values given in the literature. 